\title{
The Impact of Integrating a MOOC Platform on the Teaching of Computer Science Course: A Case Study
}

\author{
Mohssen Hakami (Corresponding author) \\ College of Sciences and Arts, Najran University, Saudi Arabia \\ E-mail:mahakami@nu.edu.sa
}

Received: February 22, 2019 Accepted: March 27, 2019 Published: April 4, 2019

doi:10.5296/jei.v5i1.14396 URL: https://doi.org/10.5296/jei.v5i1.14396

\begin{abstract}
The present study reports an attempt to identify and evaluate the effectiveness of integrating teaching MOOC platform into traditional learning system to teach a face-to-face course. It investigated students' opinions of Sharurah College of Science and Arts about the benefits and challenges based on their learning experiences in a hybrid learning environment. The researcher used both quantitative and qualitative methods to address the research questions. The study shows the following findings: a MOOC platform, as a new source for learning, supports teaching and learning in a hybrid learning environment; it can be used to support traditional learning; students like and are interested in a hybrid MOOC learning environment; and, finally, the most challenges affecting the hybrid MOOC environment are Internet drop/low speed connections and limited time for discussion in the MOOC.
\end{abstract}

Keywords: MOOC platform, Teaching, Computer science

\section{Introduction}

Massive Open Online Courses (MOOCs) have recently become one of the learning environments models in higher education (HE). The basic idea of this learning environment is to design a web learning environment that provides open access content for unlimited students all over the world with no fees (or a tiny amount). Consequently, the large spread of MOOCs has made a number of education experts adopt the view that learning for the future generations will take place through the MOOCs and will compete traditional learning environment. For example, in her article, "The year of the MOOC", Pappano (2012) stresses that the future of learning is the use of MOOCs, since these courses are taught by world-renowned professors and can provide a great deal of participation and interaction compared with traditional learning system. Moreover, since each course aims to cover educational material as determined by its author or designer, learners have the opportunity to choose the course which meets his/her needs and desires, with no need to join or enroll in the 
traditional classes (Treves, 2013; López-Sieben et al., 2014).

Conversely, some writers argue that learners need to be guided and assisted during their learning process to fulfil a better learning. This is one of the important arguments supporting the views of a number of writers and researchers who argue that universities will remain the main source of knowledge and science, especially those sciences which need to be practiced and applied. Another factor that supports the view that the MOOC system will not overwhelm the formal university education system is the criticism of the quality of some MOOCs. It has been noted that although a large number of the designed and published courses were good and enabled or helped students to learn, a number of other MOOCs neither met the required scientific standards nor achieved learning goals as set out in the course description (Banerjee $\&$ Duflo, 2014). Another factor is that students place high value on faculty interaction in the classroom (Chingos et al., 2014,). Hence the MOOC system is accepted as the panacea for all education problems, but it can be said that via the MOOC's platform, a learning system can be developed. This development can be made possible by using the MOOC system to support teaching in the classroom by mixing it in a hybrid arrangement with the educational systems rather than relying entirely on the MOOC (Rieber, 2017; Garcia-Penalvo et al., 2018).

In general, MOOCs may share with traditional learning environments in adopting common learning methods such as meeting a timetable and assessing the learner's level of learning through these courses. In his paper, Anders (2015) concludes that "hybrid MOOCs can provide supportive environments in which participants develop the experience and confidence necessary to be successful in more open and distributed learning contexts" (p. 56). He suggests that hybrid MOOCs can provide one of four innovative learning platforms, each of which has specific affordances which are different from other ones. He argues that the theoretical background and desired type of learning outcome can shape how MOOCs can be hybridized with traditional learning. In his classification, content-based hybrids pay more attention to high-quality instructional materials, whereas community-based hybrids offer more opportunities for sharing values, knowledge, and/or collective goals through socially-engaging activities. On the other hand, task-based hybrids support the development of a specific project or discrete skills. Finally, network-based hybrids benefit from social networks to develop specific knowledge that addresses situated problems. The core concept here is that the designers of MOOCs should use technology affordances and knowledge to tailor course designs to support a better teaching and learning environment. Designers should take account of the possibility that students can limit their interaction to share and compare information, and that a few highly-engaged students can increase such interaction (Tawfik et al., 2017).

In a study that focused on assessing the applicability of a MOOC platform to teach first-class physics students worldwide, it was found that, although a large number of students enrolled in the course, only 240 students out of 16,000 completed it (Olsen, 2014). Zhu et al. (2017) also reported that only $10 \%$ of students had completed their MOOCs. This behaviour is relatively evident when comparing the number of students completing a course when a MOOC is mixed with other educational systems, and when it used alone. This is supported by the findings of Treves (2013) who combined a MOOC and a flipped learning environment to 
provide a number of educational activities in order to improve students' Web Map design when they learn outside the classroom. This researcher found that $90 \%$ of his students completed the activities related to his course, and they were very positive about the method of teaching the course. Meek et al (2017) concluded that when mixing a MOOC with a traditional one, their results showed that students' performance in the written topic summary correlated with higher participation of students in the integral peer review task. Similarly, Griffiths et al. (2014, p. 4) reported that, "students in the hybrid sections did as well or slightly better than students in the traditional sections in terms of pass rates and learning assessments".

What can be concluded from the above experiences is that teaching in hybrid MOOCs may increase the opportunity for an environment which more effectively supports students' learning. In this context, Al-Atabi and DeBoer (2014) examined the appropriateness of using the MOOC platform in teaching entrepreneurship rather than teaching this subject in the traditional way. Their study revealed that the MOOC environment was compatible with the nature of entrepreneurship teaching in providing a service of participation and cooperation, which develops the learners personal attributes such as recognition of opportunities and exploitation of resources. In addition, Li et al. (2014) found that watching video during group discussion of a subject enhanced students' learning in these groups, and that the more times the video was paused for discussion, the more successful was the achievement of the learning outcomes. In general, initial studies of learning in MOOCs primarily focus on describing the arrangement and how it can be applied in education system, whereas only a few studies address and examine participants' experiences and to what extent they learn according to this new system. This is especially so in the case of those studies drawn from and directed towards Arab countries in general and Saudi Arabia in particular.

\section{Study Context}

This study aimed to investigate and evaluate teaching and learning practices featuring the use of the MOOC platform in supporting teaching in HE, and particularly to provide insights of the learning context and how the integration of the MOOCs supported students' learning. Hence, the purpose of this study was to address the following three research questions:

$\checkmark$ To what extent can using MOOCs contribute to improving a traditional teaching and learning environment in HE?

$\checkmark$ To what extent can students be satisfied with integrating a MOOC system into their traditional HE learning system?

$\checkmark$ What are the most significant challenges when integrating a MOO system into the traditional teaching and learning environment in HE?

The study took place at Sharurah College of the Science and Arts where students have the opportunity to study a face-to-face course integrated with a MOOC matching its learning syllabus. The face-to-face course is one of the author's courses which was taught on the campus and is called "Computer Education". It was delivered in the first semester of the academic year 2015/2016 with 21 enrolled students. The MOOC was taught by a staff 
member at the Faculty of Graduate Studies, Cairo University. She is a specialist in educational technology; her MOOC was a free course about "E-learning and designing educational content", delivered via Rwaq platform from 23 November, 2015 to 04 March, 2016 (14 weeks). The MOOC has been seen as one of the resources to facilitate task-based learning in order to design a better teaching learning environment (Tawfik et al., 2017). Thus, during the face-to-face classroom sessions, the researcher aimed to involve students in interactive activities, benefiting from those learning materials being asked to accomplish through attending the MOOC. In each session, the students were divided into 4 learning groups, and each group was given a task. In doing so, the author's role as a teacher, research was to monitor the students' performance and assess how they benefited from the learning materials, provided by the MOOC instructor, which he asked them to fulfill before each session.

\section{Method and Sample}

A case study approach was selected in order to obtain comprehensive answers to the research questions and so to have a better understanding of how students learned and interacted in the hybrid learning system and to what extent they were satisfied with learning environment. Hence, both quantitative and qualitative methods were used to assess the integration of the MOOC system into the traditional HE teaching and investigate the benefits/gains or challenges that hindered learning in this new learning environment. Thus, qualitative data were used to illuminate how the MOOC system was used in teaching setting, how students used it for their learning, and their views on ways of improving the hybrid learning environment. To achieve this, a focus group interview was regarded as the best method to get students' accounts and views on the value of learning in a hybrid learning system, together with detail of how they applied it. Six students agreed to participate, and a semi-structured interview was arranged. On the other hand, a quantitative method was used to identify students' perspectives about the challenges, if any, that they faced and to what extent the hybrid learning system supported or hindered their learning. Accordingly, a questionnaire was distributed to collect the required quantitative data and to provide qualitative data through responses to two open- ended questions. The questionnaire was reviewed by three researchers and their comments were taken into consideration before modifying and applying it. Eighteen of the 21 enrolled students participated and responded to the questionnaire. The qualitative data were analyzed following the qualitative content analysis approach discussed by Stewart and Shamdasani (2014).

\section{Results and Discussion}

As this study used both quantitative and qualitative methods, data were coded by looking for significant statements and key codes which are related to the purpose of the study. Accordingly, the codes were grouped and compared based on the differences and similarities. Both types of data sets were analyzed together to elaborate the findings; when relevant the author compared the study findings with those reported in the literature (Creswell, 2009).

The descriptive variables (type of computer owned, computer experiences, Internet access, the daily use of the Internet per hour, and participants' experiences of using MOOCs) were 
identified as the descriptive statistics as shown in Table 1 below:

Table 1. Descriptive statistical analysis

\begin{tabular}{|l|l|l|l|l|l|l|l|l|l|}
\hline $\begin{array}{l}\text { Type of } \\
\text { computer owned }\end{array}$ & \multicolumn{2}{l}{$\begin{array}{l}\text { Computer } \\
\text { experiences }\end{array}$} & \multicolumn{2}{|l|}{ Internet access } & \multicolumn{2}{l|}{$\begin{array}{l}\text { Daily use of the } \\
\text { Internet per hour }\end{array}$} & \multicolumn{2}{l|}{$\begin{array}{l}\text { MOOCs } \\
\text { experiences }\end{array}$} \\
\hline $\begin{array}{l}\text { Laptop or } \\
\text { desktop }\end{array}$ & 8 & Expert & 5 & DSL & 10 & $1-3$ & 7 & $\begin{array}{l}\text { One course } \\
\text { at least }\end{array}$ & 10 \\
\hline Smartphone & 9 & Skilled & 11 & $3 \mathrm{G} / 4 \mathrm{G}$ & 9 & $4-6$ & 8 & $\begin{array}{l}\text { I read } \\
\text { about it }\end{array}$ & 5 \\
\hline I don't own & 1 & Beginner & 2 & $\begin{array}{l}\text { DSL }+ \\
(3 \mathrm{G} / 4 \mathrm{G})\end{array}$ & 1 & More than 6 & 3 & $\begin{array}{l}\text { I don't know } \\
\text { what it is }\end{array}$ & 3 \\
\hline
\end{tabular}

Table 1 shows that 16 out of 18 participants are skilled users of computer; most of them own a device to connect the Internet whereas only one participant does not own a computer. However, according to his answer in the questionnaire, he is able to use computer skillfully. Most participants had some idea about MOOC systems since 15 out of 18 reported that they at least read about the MOOC system. All participants use the Internet daily for at least an hour per day even by using the DSL/3G-4G or both services to connect to the Internet.

Results show that students are interested in learning in the hybrid learning environment, particularly those students who have a positive attitude towards MOOCs' learning platform and prior experience in using it. As student (ST) 4 reported "I like the MOOCs learning system and I used to use it to learn, I found it useful to be used to support my learning during the lessons". Moreover, some students thought that MOOCs can provide a new space to facilitate face-to-face learning. For example, ST2 indicated that in some lectures he had found it difficult to obtain full comprehension of some subjects, but when he reviewed a subject in the MOOC, he had much more comprehension of it. According to students' responses to the questionnaire, 10 out of 18 participants indicated that they have prior experience in using a MOOC's learning platform since they had at least participated on one MOOC in the past. Students considered the MOOC a useful tool which can be used to provide them with a basic idea of any subject. As a result, their comprehension became faster during the face-to-face lecture. ST5 reported "I found it more useful to have information about the lecture subject prior the lecture". This is maybe one of the reasons that led 14 out of 18 students to agree that "it is important to support traditional learning system with a MOOC". However, at the same time, students believe "it is important to attend traditional classroom" as reported by 13 out of 18 students.

It can be concluded that students are more likely to regard the MOOC's learning platform as a tool supporting their traditional learning at university rather than as a new autonomous 
system which can be used instead of face-to-face interactions. However, when students were asked to what extent they agreed/disagreed with the statement, "For my formal learning, I prefer using MOOC's learning platform rather than using traditional learning system", 10 out of 18 students agreed. Furthermore, 10 out of 18 students disagreed with the statement, "I wish that all courses at the university were taught by the traditional learning system". Basically, it can be said that students' positive attitude towards the MOOC's learning platform is one of the important factors that led students to use it to support their learning. As result, students regard the hybrid MOOC platform as a good learning environment that can be used to improve their learning performance at the classroom. This explains why 14 out of 18 students reported that they were satisfied with their level of performance in this course. ST2 concluded that "MOOC courses will not terminate universities' learning, but it is one way to support us to gain more knowledge". This finding is consistent with Al-Atabi and DeBoer (2014) and Meek et al. (2017) who think that hybrid learning offers more opportunity to support students' learning and achievement.

As already mentioned, students benefitted from attending MOOC since they could pace their online learning to reach a better comprehension when they were using the MOOC's platform to support their learning outcomes. Additionally, only 8 out of 18 students thought that a MOOC system could support their learning in a science course. Furthermore, only 9 out 18 students opined that a MOOC platform could support their learning in the courses they study in their first academic year. Furthermore, almost half of the participants commented that they did not have full autonomy to discuss a specific aspect or topic with their MOOC's teacher. In other words, students' involvement in learning activities such as group discussion is limited in a MOOC. One reason for that is that students tend to use the MOOC's platform to $\mathrm{read} /$ watch learning materials rather than involving in a real discussion with the MOOC's teacher. As ST6 indicated "I don't have time to ask MOOC course teacher about the lesson I just repeat the video clip presented in the platform". Similarly, ST3 reports that "it is time consuming to ask and wait for an answer from the MOOC's teacher". This might explain the students' view that "it is important to attend traditional classroom" as reported by 13 out of 18 students.

However, other studies reveal that MOOC's system still has the opportunity to offer a flexible learning environment based on the wants and needs of students (López-Sieben et al., 2014; Rieber, 2017). In this study, almost three quarters of the participants indicated that the hybrid MOOC has attracted them to learn. ST4 reports that "I liked joining the hybrid MOOC course ... it is a good way to review learning subject since it provides a list of learning materials ... I can study at any time". ST5 links the benefits of the hybrid MOOC to the discussion followed in the classroom, stating "I found it difficult for me to contact with MOOC's teacher but when I attend the classroom I reviewed with my colleague things I couldn't understand ... and also have the opportunity to ask the teacher in classroom". What we notice here is that live faculty interaction in the classroom, as revealed by other studies (Chingos et al., 2014; Garcia-Penalvo et al., 2018), is one factor that more likely increases the benefits of MOOC's platforms when made available in conjunction with a hybrid MOOC's platform. As ST2 explains "by mixing MOOC platform with lessons in this course I think we 
got more time to review the subjects at home and find answer for our questions by the teacher in the classroom".

Since the MOOC syllabus is not exactly consistent with the course being taught in the classroom by the researcher, students reported that they found it confusing when the MOOC teacher presented more information than was directly related to their course. However, some students considered it a good way to broaden their minds about other aspects related to the same subject. As ST1 reported "in some subjects MOOC's teacher gives more details and information not linked to what have being discussed in the classroom ... But I think it is good". Additionally, students reported some positive experiences with learning activities. ST4 said "... it is hard to say that MOOC course did not give us a new way of learning. I used to come to the lecture with no prior idea about the subject of the lesson but now I could attend the lesson in advance". This way of learning also encourages students to find out more information about the subject via other resources. ST5 reported "sometimes, I find the information presented by the MOOC teacher is not clear to me, so I had to use the Internet to find more information about the subject in the WEB". Additionally, students found this way of learning was time consuming and kept them busy all the time because of drop Internet or low speed connection to the Internet. As ST3 responded "the low speed of the Internet is one of the most challenges which prevent me to attend the MOOC lessons and find more information about the subject". This may explain why 12 out of 18 agreed with the statement "in comparison with the normal teaching and learning, I am not satisfied with this type of teaching and learning".

It can be argued here that the obstacles which students faced when taking part in the MOOC can be seen as one of the reasons that reduced students' preference to learn in a hybrid MOOC environment. Indeed, students reported that lack of reliable high-speed internet hindered their being fully involved in the MOOC. As a result, they could not perform the learning task being asked of them. ST5 indicated that "I found it embarrassing to me when I came to some lessons and I didn't attend the lesson in the MOOC course" as he faced problems with Internet connection most of the time. However, when students were asked, "To what extent do you agree/disagree with the statement: 'in my view it is important to support normal teaching and learning with MOOCs", 14 out 18 agreed. Again, it is more likely that students have a positive attitude towards the use of hybrid MOOC. However, the challenges they faced outside the classroom affected their willingness to study in a hybrid MOOC learning platform. When students were asked to what extent they agreed/disagreed with the statements "I get much learning outcome when involved in learning activities during the lessons", 17 out of 18 students agreed. What can be said here is that students like the hybrid MOOC platform, but the obstacles they encountered when applying it reduced their satisfaction with this type of learning. Yet 14 out 18 students agreed with the statement "Via hybrid MOOC learning environment, I gain more knowledge". Moreover, 15 out 18 students indicated that they were satisfied with their performance in this course.

Students reported exercising and developing collaboration skills in their daily practice by getting involved in different learning activities in/out the classroom. Likewise, students exercised individual skills to learn in the hybrid MOOC environment. ST1 regards the 
MOOC platform as a helpful resource which he can use individually at home to increase his understating, not only in this course but also as a learning resource for other courses; he indicated "I found the MOOC platform more helpful than other learning tools because I could increase my comprehension of any subject". Furthermore, other students considered the hybrid MOOC a better way for them to collaborate during the lesson time and discuss what they learned previously via the MOOC teacher. As ST5 reported "In fact, during the lectures, I found it more useful to discuss with my collogue in the group". The students think that this is one of the most benefits they gained from learning in the hybrid MOOC environment since they could apply this way of learning to other courses by using the MOOC platform as a source/tool to increase their comprehension.

\section{Conclusions}

Teaching and learning in a hybrid MOOC environment give more opportunities for students to review their course content before attending the classroom. Moreover, the teachers find it a more useful way to increase students' learning outcomes because they cover more information about the subject and has more time to discuss the subject in depth with his students during the lesson time. In other words, the MOOC platform has become regarded as a new source for learning to support teaching and learning in a hybrid learning environment.

The results of this study show that students like and are interested in the hybrid MOOC learning environment. However, there are a few suggestions for enhancement which emerge from analysis of the data. First, learning should not be relayed solely on MOOC platform nor merely on the HE traditional learning system as featured in other studies (Rieber, 2017; Garcia-Penalvo et al., 2018). Students think the hybrid MOOC arrangement is a better way to benefit from the advantages of both learning systems. However, Tawfik et al. (2017) point out that the teacher/designer needs to tailor his/her course to meet students' learning needs. Second, although students' expressed satisfaction with the learning structure of this course, the MOOC system that has been selected needs to be rendered more attractive by offering instant answers to the learners' questions. Third, matching between traditional course syllabi and the MOOC needs to be more consistent in order to help students to meet the learning outcomes of the course.

In this study, the greatest challenge affecting the hybrid MOOC environment was the Internet drop/low speed connections. In fact, this factor has been expected to be reported by students in other studies. The poor Internet service at Sharurah city needs to be taken into consideration when applying such a learning system. The students also regarded the limited time for discussion in the MOOC platform as one of the obstacles which did not encourage them to prefer learning through this type of learning environment. However, students still considered the MOOC platform a good way for learning especially when integrated with traditional learning in a hybrid learning environment.

Accordingly, this study does not contribute empirical evidence. The author rather argues that it contributes to understanding how students learn in a hybrid learning environment and the potential to support teaching and learning environment. Another contribution is that the MOOC platform can be used to support traditional learning in which the teacher benefits 
from other teacher's experiences, knowledge and support.

\section{Acknowledgements}

This research paper is funded by Deanship of Scientific Research at the University of Najran. (NU/SHED/14/208).20.0.

\section{References}

Al-Atabi, M., \& DeBoer, J. (2014). Teaching entrepreneurship using massive open online course (MOOC). Technovation, 34(4), 261-264.

Anders, A. (2015). Theories and applications of massive online open courses (MOOCs): The case for hybrid design. The International Review of Research in Open and Distributed Learning, 16(6).

Banerjee, A. V., \& Duflo, E. (2014). (Dis)organization and success in an economics MOOC. American Economic Review, 104(5), 514-18.

Creswell, J. W. (2009). Mapping the field of mixed methods research. SAGE Publications Sage CA: Los Angeles, CA.

Garcia-Penalvo, F. J., Fidalgo-Blanco, Ã., \& Sein-Echaluce, M. L. (2018). An adaptive hybrid MOOC model: Disrupting the MOOC concept in higher education. Telematics and Informatics, 35(4), 1018-1030.

Chingos, M., Mulhern, C., Griffiths, R., \& Spies, R. R. (2014). Interactive Online Learning on Campus. Testing MOOCs and Other Platforms in Hybrid Formats in the University System of Maryland. Retrieved from https://sr.ithaka.org/publications/interactive-onlinelearning-on-campus

López-Sieben, M., Peris-Ortiz, M., \& Gómez, J. A. (2014). Lessons learned through massive open online courses. In M. Peris-Ortiz, F. Garrigós-Simón, \& I. Gil Pechuán (Eds.), Innovation and Teaching Technologies (pp. 11-21). Springer, Cham.

Li, N., Verma, H., Skevi, A., Zufferey, G., Blom, J., \& Dillenbourg, P. (2014). Watching MOOCs together: Investigating co-located MOOC study groups. Distance Education, 35(2), 217-233.

Meek, S. E. M., Blakemore, L., \& Leah, M. (2017). Is peer review an appropriate form of assessment in a MOOC? Student participation and performance in formative peer review. Assessment \& Evaluation in Higher Education, 42(6), 1000-1013.

Olsen, J. R. (2014). Comparative Analysis of a MOOC and a Residential Community Using Introductory College Physics: Documenting How Learning Environments Are Created, Lessons Learned in the Process, and Measurable Outcomes. Retrieved from https://scholar. colorado.edu/phys_gradetds/115

Pappano, L. (2012). The year of the MOOC. The New York Times, 2(12).

Rieber, L. P. (2017). Participation patterns in a massive open online course (MOOC) about 
statistics. British Journal of Educational Technology, 48(6), 1295-1304.

Stewart, D. W., \& Shamdasani, P. N. (2014). Focus groups: Theory and practice, Sage publications. Retrieved from https://www.amazon.com/Focus-Groups-Practice-AppliedResearch/dp/0761925821

Tawfik, A. A., Reeves, T. D., Stich, A. E., Gill, A., Hong, C., McDade, J., .. Giabbanelli, P. J. (2017). The nature and level of learner-learner interaction in a chemistry massive open online course (MOOC). Journal of Computing in Higher Education, 29(3), 411-431.

Treves, R. (2013). Flipped Learning, MOOCs and Learning Analytics: Lessons learnt from a Web Map Design course redesign. AGU Fall Meeting Abstracts.

Zhu, Y., Pei, L., \& Shang, J. (2017). Improving video engagement by gamification: A proposed design of MOOC videos. International Conference on Blended Learning, Springer.

\section{Copyright Disclaimer}

Copyright for this article is retained by the author(s), with first publication rights granted to the journal.

This is an open-access article distributed under the terms and conditions of the Creative Commons Attribution license (http://creativecommons.org/licenses/by/3.0/). 